\title{
Chemotherapy for urothelial carcinoma in renal transplantation patients: Initial results from a single center
}

\author{
YICHEN ZHU*, JING XIAO*, YUWEN GUO, JUN LIN, LEI ZHANG and YE TIAN \\ Department of Urology, Beijing Friendship Hospital Affiliated to Capital Medical University, \\ Beijing 100050, P.R. China
}

Received February 4, 2015; Accepted June 4, 2015

DOI: $10.3892 / \mathrm{mco} .2015 .615$

\begin{abstract}
The aim of this study was to assess the safety and efficacy of gemcitabine plus cisplatin/carboplatin (GC/GCa) chemotherapy in renal transplantation (RT) patients with urothelial carcinoma (UC). We reviewed the records of 12 RT patients with metastatic or locally advanced UC who received chemotherapy at our institution since January, 2013. All the patients received intravenous gemcitabine $\left(800 \mathrm{mg} / \mathrm{m}^{2}\right)$ on days 1,8 and 15 , plus cisplatin $\left(70 \mathrm{mg} / \mathrm{m}^{2}\right)$ or carboplatin (area under the curve $=5$ ) on day 2 , every 28 days. A total of 10 patients completed all the cycles, while 1 patient discontinued treatment due to disease progression and 1 patient discontinued due to non-medical reasons. In total, 12 patients received a median of four cycles of chemotherapy. The overall response rate was $50 \%$ (4/8 cases) in patients with measurable lesions. At the time of the study, 5 patients had succumbed to the disease (overall survival, 9.2 months), while 7 patients remained alive (follow-up time, 13.3 months). The most
\end{abstract}

Correspondence to: Dr Ye Tian, Department of Urology, Beijing Friendship Hospital Affiliated to Capital Medical University, 95 Yong'an Road, Xicheng, Beijing 100050, P.R. China

E-mail: yetian166@gmail.com

*Contributed equally

Abbreviations: GC/GCa, gemcitabine plus cisplatin/carboplatin; RT, renal transplantation; UC, urothelial carcinoma; AUC, area under the curve; PTLD, post-transplantation lymphoproliferative disorder; CBC, complete blood count; ALT, alanine aminotransferase; $\mathrm{SCrC}$, serum creatinine concentration; GFR, glomerular filtration rate; CT, computerized tomography; CTCAE, Common Terminology Criteria for Adverse Events; RECIST, Response Evaluation Criteria in Solid Tumors; OS, overall survival; PFS, progression-free survival; ECOG, Eastern Cooperative Oncology Group; G-CSF, granulocyte colony-stimulating factor; $\mathrm{CR}$, complete response; $\mathrm{PR}$, partial response; $\mathrm{SD}$, stable disease; $\mathrm{PD}$, progressive disease; UTUC, upper tract urothelial carcinoma; mTOR, mammalian target of rapamycin; CNI, calcineurin inhibitor

Key words: chemotherapy, renal transplantation, urothelial carcinoma common toxicities were myelosuppression and gastrointestinal effects. Therefore, the $\mathrm{GC} / \mathrm{GCa}$ regimen was found to be effective and tolerable in RT patients with UC. However, further studies involving more patients and control groups are required to confirm our results.

\section{Introduction}

The short-term survival of renal transplantation (RT) patients has increased significantly over the last few years, as a result of the development of immunosuppressive drugs, modification of immunosuppressive regimens and improved techniques in organ handling (1). The long-term survival of RT patients, however, has not improved significantly (1). The increased incidence of cancer due to the longer life span and chronic exposure to immunosuppressive drugs may play an important role in the lack of long-term improvement $(2,3)$. A recent large-scale study involving 175,732 solid organ transplant recipients (58.4\% kidney, $21.6 \%$ liver, $10.0 \%$ heart and $4.0 \%$ lung) demonstrated that the overall cancer risk, with 10,656 cases and an incidence of 1,375 per 100,000 person-years, has increased significantly compared to that in the non-transplant population (4). Furthermore, it was suggested that malignancy was surpassing cardiovascular disease as the leading cause of long-term post-transplantation mortality (5).

China has experienced a similar trend. Indeed, according to our published data, urothelial carcinoma (UC) is the predominant malignancy among Chinese RT patients (6-9). This is quite different from Western countries, in which non-melanoma skin cancer and post-transplantation lymphoproliferative disorder (PTLD) are the most common malignancies $(10,11)$. Although surgical intervention is recommended, due to the rapid progression, post-transplantation UC is generally intractable and is associated with a poor prognosis $(5,10)$.

Recently, cisplatin/carboplatin-based chemotherapy has been considered to be an effective treatment for locally advanced and metastatic UC (12). However, to the best of our knowledge, no study has yet investigated platinum-based chemotherapy in RT patients with UC. Renal toxicity and the potential risk of infection are likely the factors of greatest concern for physicians, thus preventing them from performing chemotherapy on RT patients. In our center, chemotherapy has been performed in RT patients with UC over several years. The purpose of this retrospective study was to initially assess the 
feasibility of gemcitabine plus cisplatin/carboplatin (GC/GCa) chemotherapy in post-RT UC patients.

\section{Patients and methods}

Patients and evaluation. Between January, 2013 and September, 2014, 12 RT patients who suffered from UC were included in the study. All the patients were histologically diagnosed with muscle-invasive or advanced UC. The patient medical records were retrospectively reviewed for data on demographics, previous transplantation history, radiological, pathological and surgical information and chemotherapy history. During all the cycles of chemotherapy, the complete blood count (CBC), urine routine test and biochemistry evaluation, including aspartate aminotransferase (AST), alanine aminotransferase (ALT), albumin and serum creatinine concentration (SCrC) were evaluated weekly. Glomerular filtration rate (GFR), computerized tomography (CT) scans of the chest, abdomen and pelvis, and radionuclide bone scans were evaluated every two cycles. Toxicity was graded according to the Common Terminology Criteria for Adverse Events scale, version 4.0 (13). The response category was determined using the Response Evaluation Criteria in Solid Tumors 1.1 (14).

Chemotherapeutic regimen. The eligibility criteria for chemotherapy were as follows: i) age $\geq 18$ years; ii) Eastern Cooperative Oncology Group (ECOG) performance score $\leq 3$; iii) adequate hematological and hepatic function (white blood cell count $\geq 3.5 \times 10^{9} / 1$, absolute neutrophil count $\geq 1.5 \times 10^{9} / 1$, platelet count $\geq 100 \times 10^{9} / 1$, albumin level within normal limits, ALT and AST $\leq 2$-fold the upper normal limit (for liver metastatic cases, $\leq 5$-fold the upper normal limit); iv) normal renal function (GFR $\geq 30 \mathrm{ml} / \mathrm{min} / 1.73 \mathrm{~m}^{2}$, absence of proteinuria and $\mathrm{SCrC} \leq$ upper normal limit). Hospitalization was required for treatment on the day the chemotherapeutic drugs were administered. The patients received gemcitabine $\left[800 \mathrm{mg} / \mathrm{m}^{2}\right.$ as a 30-min intravenous (i.v.) infusion] on days 1, 8 and 15 separately, and cisplatin (70 $\mathrm{mg} / \mathrm{m}^{2}$ as a 2-h i.v. infusion) on day 2 every 4 weeks (GC regimen). For cases with impaired renal function, cisplatin was replaced by carboplatin (area under the curve $=5$; GCa regimen). Hematopoietic growth factor supportive therapy was required in cases with severe ( $\geq$ grade 2 ) marrow suppression. If the patients did not meet the eligibility criteria at the beginning of a cycle, the cycle was delayed until recovery. Treatment was discontinued in patients exhibiting disease progression or in cases of unacceptable toxicity.

Statistical method. The response rate, overall survival (OS) and progression-free survival (PFS) were measured at the time point of present study. OS was estimated by the Kaplan-Meier method, with the time measured from the first day of treatment.

\section{Results}

Patient characteristics. The characteristics of the 12 patients with UC are summarized in Table I. The reason for offering chemotherapy was detected metastatic lesions $(\mathrm{M}+)$ during
Table I. Baseline patient characteristics

\begin{tabular}{lc}
\hline Characteristics & No. $(\%)$ \\
\hline Age, years (mean \pm SD) & $55.17 \pm 8.79$ \\
Time of transplantation, & $11.0 \pm 2.33$ \\
years (mean \pm SD) & \\
Immunosuppressive regimen & \\
FK506+MMF+P & $5(41.7)$ \\
Rapamycin+MMF+P & $1(8.3)$ \\
CsA+MMF+P & $6(50.0)$ \\
ECOG performance status & \\
0 & $10(83.3)$ \\
1 & $2(16.7)$ \\
$\geq 2$ & $0(0.0)$
\end{tabular}

\section{Histology}

Pure transitional cell carcinoma

Urothelial and SCC

Primary UC sites

UTUC alone

UTUC + BC

Previous treatment

RNU only

RNU+TUR-Bt

$\mathrm{RNU}+\mathrm{RC}$

TNM stage at presentation

T2-4NOMO

$\mathrm{TxN}+\mathrm{M} 0$

TxNxM+

Metastatic sites

Bone 3

Lung 2

Liver

Lymph nodes

Peritoneum

Pelvic cavity

Cisplatin eligibility

Yes

No

Biological parameters (base line)

GFR $\left(\mathrm{ml} / \mathrm{min} / 1.73 \mathrm{~m}^{2}\right)$

$62.56 \pm 6.53$

WBC count $\left(\times 10^{9} / 1\right)$

$5.57 \pm 1.33$

PLT count $\left(\times 10^{9} / 1\right)$

$238.33 \pm 66.31$

SD, standard deviation; SCC, squamous cell carcinoma; MMF, mycophenolate mofetil; P, prednisone; CsA, cyclosporin A; ECOG, Eastern Cooperative Oncology Group; UC, urothelial carcinoma; UTUC, upper tract UC; BC, bladder cancer; RNU, radical nephroureterectomy; TUR$\mathrm{Bt}$, transurethral resection of bladder tumor; RC, radical cystectomy; GFR, glomerular filtration rate; WBC, white blood cell; PLT, platelet.

the postoperative follow-up $(n=6)$, postoperative histological diagnosis confirming positive lymph nodes $(n=3)$ and only muscle-invasive disease $(\geq T 2, n=3)$. All the cases had a 
Table II. Cycle delay and dose reduction.

\begin{tabular}{lcccc}
\hline & \multicolumn{4}{c}{ Cycles } \\
\cline { 2 - 5 } & 1 & 2 & 3 & 4 \\
Characteristics & $(\mathrm{n}=12)$ & $(\mathrm{n}=12)$ & $(\mathrm{n}=10)$ & $(\mathrm{n}=10)$ \\
\hline Number of cycles delayed & 0 & 1 & 3 & 4 \\
Reason for cycle delay & & & & \\
$\quad$ Myelosuppression & 0 & 0 & 2 & 2 \\
Renal toxicity & 0 & 1 & 1 & 1 \\
$\quad$ Other & 0 & 0 & & 1 \\
Number of dose reductions & 0 & 1 & 2 & 2 \\
Reason for dose reduction & & & & \\
$\quad \begin{array}{l}\text { Myelosuppression } \\
\text { Renal toxicity }\end{array}$ & 0 & 0 & 1 & 1 \\
\hline
\end{tabular}

history of exposure to aristolochic acid. The primary UC site included the upper tract and bladder in 11 cases and the upper tract alone in 1 case. In all the cases, SCrC was normal and only 1 patient was ineligible for cisplatin treatment due to a GFR of $<60 \mathrm{~min} / \mathrm{ml}$, in which case cisplatin was replaced by carboplatin.

Treatment. All the patients received at least one cycle of GC chemotherapy, with a median number of four cycles (range, 1-8 cycles). One patient discontinued treatment due to disease progression and 1 patient discontinued due to non-medical reasons. The remaining 10 patients completed the therapy. The treatment delays and dose reductions are shown in Table II.

Toxicity. Overall, the GC regimen was well tolerated. Myelosuppression was the most common toxicity (10/12) and was also the main reason for cycle delay and dose reduction. A total of 5 patients with grade 2-3 granulocytopenia received granulocyte colony-stimulating factor (G-CSF) treatment. Nausea and vomiting (7/12) were the most common non-hematological toxicities, but they were mild (grade 1-2). Renal toxicity, which was the greatest concern for both physicians and RT patients, was mild. Renal injury (grade 1) and proteinuria (grade 1) were detected in only 2 cases, and both patients recovered quickly without further treatment. The treatment-related adverse events are summarized in Table III.

Response and survival. Of the 8 patients with measurable lesions, 1 achieved complete response (CR) and 3 achieved partial response (PR) (overall response rate, 50\%). Pain relief was achieved in 1 case. A total of 2 patients had stable disease (SD). Only 1 patient exhibited progressive disease (PD) during chemotherapy. At the time of this study, 5 patients had succumbed to the disease [mean OS, 9.2 months; 95\% confidence interval (CI): 6.5-12.0 months). Of the 7 surviving patients at the 13.3-month follow-up, 3 exhibited PD. For all the cases with PD, the mean PFS was 7.8 months (95\% CI: 4.0-11.5 months). The follow-up information is summarized in Table IV.
Table III. Treatment-related toxicities.

\begin{tabular}{|c|c|c|c|c|}
\hline \multirow[b]{2}{*}{ Toxicities } & \multicolumn{4}{|c|}{ Cycles } \\
\hline & $\begin{array}{c}1 \\
(n=12)\end{array}$ & $\begin{array}{c}2 \\
(n=11)\end{array}$ & $\begin{array}{c}3 \\
(n=10)\end{array}$ & $\begin{array}{c}4 \\
(n=10)\end{array}$ \\
\hline \multicolumn{5}{|c|}{ Granulocytopenia } \\
\hline Grade 1 & 2 & 3 & 4 & 4 \\
\hline Grade 2 & 1 & 1 & 3 & 2 \\
\hline Grade 3 & 0 & 2 & 1 & 3 \\
\hline Grade 4 & 0 & 0 & 0 & 0 \\
\hline Grade 5 & 0 & 0 & 0 & 0 \\
\hline \multicolumn{5}{|c|}{ Thrombocytopenia } \\
\hline Grade 1 & 2 & 3 & 1 & 1 \\
\hline Grade 2 & 0 & 1 & 1 & 2 \\
\hline Grade 3 & 0 & 0 & 2 & 2 \\
\hline Grade 4 & 0 & 0 & 0 & 0 \\
\hline Grade 5 & 0 & 0 & 0 & 0 \\
\hline \multicolumn{5}{|l|}{ Anemia } \\
\hline Grade 1 & 1 & 2 & 3 & 3 \\
\hline Grade 2 & 0 & 1 & 1 & 2 \\
\hline Grade 3 & 0 & 0 & 0 & 0 \\
\hline Grade 4 & 0 & 0 & 0 & 0 \\
\hline Grade 5 & 0 & 0 & 0 & 0 \\
\hline \multicolumn{5}{|c|}{ Renal injury } \\
\hline Grade 1 & 0 & 1 & 1 & 1 \\
\hline Grade 2 & 0 & 0 & 0 & 0 \\
\hline Grade 3 & 0 & 0 & 0 & 0 \\
\hline Grade 4 & 0 & 0 & 0 & 0 \\
\hline Grade 5 & 0 & 0 & 0 & 0 \\
\hline \multicolumn{5}{|c|}{ Proteinuria } \\
\hline Grade 1 & 1 & 0 & 0 & 0 \\
\hline Grade 2 & 0 & 0 & 0 & 0 \\
\hline Grade 3 & 0 & 0 & 0 & 0 \\
\hline \multicolumn{5}{|c|}{ Diarrhea or constipation } \\
\hline Grade 1 & 1 & 2 & 1 & 3 \\
\hline Grade 2 & 0 & 0 & 0 & 0 \\
\hline Grade 3 & 0 & 0 & 0 & 0 \\
\hline Grade 4 & 0 & 0 & 0 & 0 \\
\hline Grade 5 & 0 & 0 & 0 & 0 \\
\hline \multicolumn{5}{|c|}{ Nausea or vomiting } \\
\hline Grade 1 & 2 & 3 & 4 & 5 \\
\hline Grade 2 & 1 & 1 & 3 & 2 \\
\hline Grade 3 & 0 & 0 & 0 & 0 \\
\hline Grade 4 & 0 & 0 & 0 & 0 \\
\hline Grade 5 & 0 & 0 & 0 & 0 \\
\hline
\end{tabular}

\section{Discussion}

In Asian countries, upper tract UC (UTUC) is more frequently observed compared with bladder involvement in RT patients with UC (6-9,11). Moreover, the incidence of multifocal lesions is considerably higher in $\mathrm{RT}$ recipients compared with that 
Table IV. Follow-up.

\begin{tabular}{lcccccc}
\hline Patients & Status & $\begin{array}{c}\text { Treatment } \\
\text { cycles }\end{array}$ & $\begin{array}{c}\text { Measurable } \\
\text { lesions }\end{array}$ & Response & $\begin{array}{c}\text { PFS } \\
\text { (months) }\end{array}$ & $\begin{array}{c}\text { Follow-up time } \\
\text { (months) }\end{array}$ \\
\hline 1 & D & 1 & + & SD & 4 & 10 \\
2 & D & 1 & + & PD & 1 & 6 \\
3 & D & 4 & + & SD & 3 & 9 \\
4 & D & 6 & + & SD & 4 & 7 \\
5 & D & 8 & + & SD & 9 & 14 \\
6 & A and P & 4 & + & CR & 15 & 12 \\
7 & A and P & 5 & - & PR & 12 & 17 \\
8 & A and P & 4 & + & SD & 14 & 7 \\
9 & A and NP & 4 & - & PR & 4 & 7 \\
10 & A and NP & 4 & - & SR & 14 & 14 \\
11 & A and NP & 4 & SD & 12 & 12 \\
12 & A and NP & 6 & - & & & 4
\end{tabular}

aPain relief. PFS, progression-free survival; D, deceased; A, alive; P, progression; NP, no progression; SD, stable disease; PD, progressive disease; CR, complete response; PR, partial response.

in the general population (61.9 vs. $23.7 \%$, respectively) (11). Aggressive biological behavior, multifocality and an immunosuppressive status render UC particularly difficult to treat in RT patients.

Surgical treatment is the first choice for UC and prophylactic bilateral nephroureterectomy is recommended when UTUC is suspected. Our previous study demonstrated that, even without any imaging abnormalities, UC morbidity in the contralateral upper tract was significantly higher (15). Furthermore, mammalian target of rapamycin (mTOR) inhibitor-based and calcineurin inhibitor (CNI)-free regimens are recommended, given that several studies demonstrated that the risk of developing de novo malignancies was significantly higher in a group of patients receiving CNI-based immunosuppression compared with a group receiving mTOR inhibitors (16). mTOR inhibitors are considered to exert anti-angiogenic effects, which may inhibit tumor growth (17). However, the prognosis of UC in RT patients remains poor.

Unfortunately, no optimal treatment is currently available, particularly for UC patients. The efficacy of platinum-based chemotherapy has been generally demonstrated in UC patients. Neoadjuvant and adjuvant chemotherapy have been shown to improve OS in muscle-invasive bladder cancer patients $(12,18)$. Furthermore, a recently published systemic review demonstrated that OS and disease-free survival may be prolonged by cisplatin-based neoadjuvant and adjuvant chemotherapy in UTUC patients (19). However, to the best of our knowledge, no report of the effectiveness of chemotherapy in post-RT UC patients has been published, which may be attributed to the fact that oncologists are concerned in regard to the potential renal toxicity from chemotherapy due to their unfamiliarity with kidney transplantations.

The present study demonstrated the feasibility of GC chemotherapy in RT patients. In cases with measurable lesions (advanced UC), the overall response rate was 50\% and the mean PFS was 7.8 months, which is similar to other published trials (20). Furthermore, the GC/GCa regimen was well tolerated in RT patients, particularly in terms of renal toxicity. With strict surveillance of renal function, we did not detect severe renal injuries, either short- or long-term. In previous trials, the major toxicities of $\mathrm{GC} / \mathrm{GCa}$ chemotherapy were myelosuppression and gastrointestinal effects (e.g., vomiting and nausea), which was also the case in our study. In the literature, grade 3-4 neutropenia and thrombocytopenia were observed in $\geq 60 \%$ of the patients $(21,22)$. Considering that immunosuppressive drugs also induce myelosuppression, we used hematopoietic growth factors to prevent severe myelosuppression in our post-RT UC patients; this may explain the fact that our toxicity data compare favorably with those of previous GC trials.

Cisplatin was replaced by carboplatin in patients with impaired renal function. Several trials have reported acceptable efficacy and toxicity for the GCa regimen in UC patients (21-23). In post-RT UC patients, renal function tended to be normal, as adequate immunosuppression was associated with a lower rate of chronic rejection, but a higher incidence of malignancy. In our study, only 1 patient was ineligible for cisplatin treatment and the GCa regimen was administered uneventfully in this case. Additional cases are required to confirm the efficacy and toxicity of the GCa regimen in RT patients with UC.

There were several limitations to this study. First, the small cohort of patients and short-term follow-up limited the possibility to assess the effect of chemotherapy on the OS. Further studies, involving more patients and a control group are required. Second, the present study included advanced UC as well as muscle-invasive UC cases, due to the small cohort of patients; therefore, the evaluation of the response rate was not rigorous. Third, a retrospective study is always associated with inherent bias.

In conclusion, $\mathrm{GC} / \mathrm{GCa}$ chemotherapy was found to be feasible and well-tolerated in RT patients with UC. The main 
toxicities were myelosuppression and gastrointestinal effects, whereas renal toxicity was mild. However, larger-scale and long-term studies are required to validate our results.

\section{Acknowledgements}

This study was supported by the Capital Health Research and Development of Special Fund (grant no. 2011-2002-05).

\section{References}

1. Lodhi SA, Lamb KE and Meier-Kriesche HU: Solid organ allograft survival improvement in the United States: The long-term does not mirror the dramatic short-term success. Am J Transplant 11: 1226-1235, 2011.

2. Collett D, Mumford L, Banner NR, Neuberger J and Watson C: Comparison of the incidence of malignancy in recipients of different types of organ: A UK Registry audit. Am J Transplant 10: 1889-1896, 2010.

3. Lanza LL, Wang L, Simon TA and Irish WD: Epidemiologic critique of literature on post-transplant neoplasms in solid organ transplantation. Clin Transplant 23: 582-588, 2009.

4. Engels EA, Pfeiffer RM, Fraumeni JF Jr, Kasiske BL, Israni AK, Snyder JJ, Wolfe RA, Goodrich NP, Bayakly AR, Clarke CA, et al: Spectrum of cancer risk among US solid organ transplant recipients. JAMA 306: 1891-1901, 2011.

5. van Leeuwen MT, Webster AC, McCredie MRE, Stewart JH, McDonald SP, Amin J, Kaldor JM, Chapman JR, Vajdic CM and Grulich AE: Effect of reduced immunosuppression after kidney transplant failure on risk of cancer: Population based retrospective cohort study. BMJ 340: c570, 2010

6. Chiang YJ, Yang PS, Wang HH, Lin KJ, Liu KL, Chu SH and Hsieh CY: Urothelial cancer after renal transplantation: An update. Transplant Proc 44: 744-745, 2012.

7. Wang LJ, Wong YC and Huang CC: Urothelial carcinoma of the native ureter in a kidney transplant recipient. J Urol 184: 728, 2010.

8. Xiao J, Zhu X, Hao GY, Zhu YC, Hou HJ, Zhang J, Ma LL, Tian Y and Zhang YH: Association between urothelial carcinoma after kidney transplsantation and aristolochic acid exposure: The potential role of aristolochic acid in HRas and TP53 gene mutations. Transplant Proc 43: 3751-3754, 2011.

9. Zhang A, Shang D, Zhang J, Zhang L, Shi R, Fu F and Tian Y: A retrospective review of patients with urothelial cancer in 3,370 recipients after renal transplantation: a single-center experience. World J Urol 33: 713-717, 2015.

10. Campistol JM, Cuervas-Mons V, Manito N, Almenar L, Arias M, Casafont F, Del Castillo D, Crespo-Leiro MG, Delgado JF, Herrero JI, et al; ATOS Working Group: New concepts and best practices for management of pre- and post-transplantation cancer. Transplant Rev (Orlando) 26: 261-279, 2012.
11. Liu GM, Fang Q, Ma HS, Sun G and Wang XC: Distinguishing characteristics of urothelial carcinoma in kidney transplant recipients between China and Western countries. Transplant Proc 45: 2197-2202, 2013.

12. Meeks JJ, Bellmunt J, Bochner BH, Clarke NW, Daneshmand S, Galsky MD, Hahn NM, Lerner SP, Mason M, Powles T, et al: A systematic review of neoadjuvant and adjuvant chemotherapy for muscle-invasive bladder cancer. Eur Urol 62: 523-533, 2012.

13. Chen AP, Setser A, Anadkat MJ, Cotliar J, Olsen EA, Garden BC and Lacouture ME: Grading dermatologic adverse events of cancer treatments: The Common Terminology Criteria for Adverse Events Version 4.0. J Am Acad Dermatol 67: 1025-1039, 2012.

14. Eisenhauer EA, Therasse P, Bogaerts J, Schwartz LH, Sargent D, Ford R, Dancey J, Arbuck S, Gwyther S, Mooney M, et al: New response evaluation criteria in solid tumours: Revised RECIST guideline (version 1.1). Eur J Cancer 45: 228-247, 2009.

15. Hou HJ, Xiao J and Tian Y: Contralateral nephroureterectomy for renal transplant recipients with unilateral upper urinary tract transitional cell carcinoma: A report of 12 cases. Transplant Proc 45: 2203-2206, 2013.

16. Schena FP, Pascoe MD, Alberu J, del Carmen Rial M, Oberbauer R, Brennan DC, Campistol JM, Racusen L, Polinsky MS, Goldberg-Alberts R, et al; Sirolimus CONVERT Trial Study Group: Conversion from calcineurin inhibitors to sirolimus maintenance therapy in renal allograft recipients: 24-month efficacy and safety results from the CONVERT trial. Transplantation 87: 233-242, 2009.

17. Geissler EK, Schlitt HJ and Thomas G: mTOR, cancer and transplantation. Am J Transplant 8: 2212-2218, 2008.

18. Leow JJ, Martin-Doyle W, Rajagopal PS, Patel CG, Anderson EM, Rothman AT, Cote RJ, Urun Y, Chang SL, Choueiri TK, et al: Adjuvant chemotherapy for invasive bladder cancer: A 2013 updated systematic review and meta-analysis of randomized trials. Eur Urol 66: 42-54, 2014.

19. Leow JJ, Martin-Doyle W, Fay AP, Choueiri TK, Chang SL and Bellmunt J: A systematic review and meta-analysis of adjuvant and neoadjuvant chemotherapy for upper tract urothelial carcinoma. Eur Urol 66: 529-541, 2014.

20. Culine S: Chemotherapy for advanced transitional cell carcinoma of the urothelium: Cisplatin or carboplatin? Eur Urol 52: 9-10, 2007.

21. Dogliotti L, Cartenì G, Siena S, Bertetto O, Martoni A, Bono A, Amadori D, Onat $\mathrm{H}$ and Marini L: Gemcitabine plus cisplatin versus gemcitabine plus carboplatin as first-line chemotherapy in advanced transitional cell carcinoma of the urothelium: Results of a randomized phase 2 trial. Eur Urol 52: 134-141, 2007.

22. Baitar A, De Vos M, Vandebroek A and Schrijvers D: Carboplatin and gemcitabine in patients with advanced and/or metastatic urothelial cancers: A phase II study. J Geriatr Oncol 2: 31-35, 2011.

23. Mertens LS, Meijer RP, Kerst JM, Bergman AM, van Tinteren H, van Rhijn BW and Horenblas S: Carboplatin based induction chemotherapy for nonorgan confined bladder cancer - a reasonable alternative for cisplatin unfit patients? J Urol 188: $1108-1113,2012$ 